\title{
MOVPE Growth of Quaternary (Al,Ga,In)N for UV Optoelectronics
}

\author{
Jung Han," Jeffrey J. Figiel, Gary A. Petersen, Samuel M. Myers, Mary H. \\ Crawford, Michael A. Banas, and Sean J. Hearne \\ Sandia National Laboratories, Albuquerque, NM 87185
}

\begin{abstract}
We report the growth and characterization of quaternary AlGaInN. A combination of photoluminescence (PL), high-resolution x-ray diffraction (XRD), and Rutherford backscattering spectrometry (RBS) characterizations enables us to explore the contours of constant- PL peak energy and lattice parameter as functions of the quaternary compositions. The observation of room temperature PL emission at $351 \mathrm{~nm}$ (with $20 \% \mathrm{Al}$ and $5 \% \mathrm{In}$ ) renders initial evidence that the quaternary could be used to provide confinement for GaInN (and possibly GaN). AlGaInN/GaInN MQW heterostructures have been grown; both XRD and PL measurements suggest the possibility of incorporating this quaternary into optoelectronic devices.
\end{abstract}

\section{INTRODUCTION}

Development of nitride-based ultraviolet (UV) emitters has thus far been overshadowed by the intense effort in the InGaN-based visible light emitters. ${ }^{1}$ The potential usage of a compact UV light source ranges from energy-efficient indoor lighting (as a white-light source), free space satellite communication, compact chemical, environmental, and biological sensing devices, applications in medical diagnosis, treatment, and possibly optical storage. With all the rewarding promises, however, the development of UV emitters faces many challenging issues. Preliminary work in the $\mathrm{AlGaN} / \mathrm{GaN}$ quantum well (QW) UV emitters ${ }^{2}$ suggested that the use of a binary GaN active region results in a low optical output power. Furthermore, mismatch-induced tensile stress was observed during growth of $\mathrm{AlGaN}$ heterostructures on thick GaN templates for UV devices, ${ }^{3}$ leading to relaxation through crack generation. Quaternary AlGaInN compound semiconductors are expected to enclose a finite (non-zero) area on the plot of energy gap versus lattice constant. In principle the employment of quaternary compounds should render flexibility in tailoring bandgap profile while maintaining lattice matching and structural integrity. In this paper we will summarize our investigation on the issues of optical efficiency and strain control using quaternary AlGaInN compound.

\section{EXPERIMENTAL DETAILS}

The MOVPE growth is carried out in a vertical rotating-disc reactor. All of the quaternary epilayers and multiple quantum well (MQW) structures were grown on 1- $\mu \mathrm{m}$ $\mathrm{GaN}$ epilayers at $1050^{\circ} \mathrm{C}$ using a standard two-step nucleation procedure (on sapphire) with low-temperature $\mathrm{GaN}$ grown at $550{ }^{\circ} \mathrm{C} .^{4}$ The growth temperature of the quaternary

*Electronic mail: jhan@sandia.gov 
$\mathrm{AlGaInN}$ was varied between 750 and $820^{\circ} \mathrm{C}$. The reactor pressure was held constant at 200 Torr. The $\mathrm{NH}_{3}$ and $\mathrm{N}_{2}$ flows were set at $6 \mathrm{l} / \mathrm{min}$ each. An additional flow of $\mathrm{H}_{2}$ $\left(\sim 400 \mathrm{~cm}^{3} / \mathrm{min}\right)$ was employed as a carrier gas. Trimethylgallium, triethylaluminum, and trimethylindium were employed as metalorganic precursors.

Given the scarcity of reliable information concerning the quaternary, it is imperative to accurately determine the concentrations of the constituent elements. Concentrations of In and $\mathrm{Al}$ in the films were measured using Rutherford backscattering spectrometry $(\mathrm{RBS})^{5}$ with a $2.5 \mathrm{MeV}^{4} \mathrm{He}^{+}$ion beam. Ion-channeling effects in the RBS spectra were randomized by tilting the sample $10^{\circ}$ from normal to the analysis beam and continuously rotating the sample about its normal during the analysis. Al and In concentrations were then extracted from the spectra using the SIMNRA (ver. 4.4) simulation program. ${ }^{6}$ Figure 1 shows a representative RBS spectrum from AlGaInN. The solid line is the fitted simulation, while the dashed line is a simulation for the same In concentration with no $\mathrm{Al}$. The inset shows a diagram of the measured film on $\mathrm{GaN}$, along with the fitted concentration values for In and Al. The large backscattering yield from In, coupled with the accurately known nuclear cross section, results in a relatively high accuracy for the determination of the In concentration. We estimate an uncertainty of \pm 0.002 at an In concentration of 0.01 , and \pm 0.005 for a concentration of 0.10 . Because the backscattering yield from $\mathrm{Al}$ is much smaller, the $\mathrm{Al}$ concentration was determined less directly by measuring a reduction, or dip, in the yield from $\mathrm{Ga}$, due to the presence of the $\mathrm{Al}$ and $\mathrm{In}$ in the layer. An uncertainty of \pm 0.01 at an $\mathrm{Al}$ concentration of 0.10 , and \pm 0.02 for a concentration of 0.20 was estimated for the cited data.

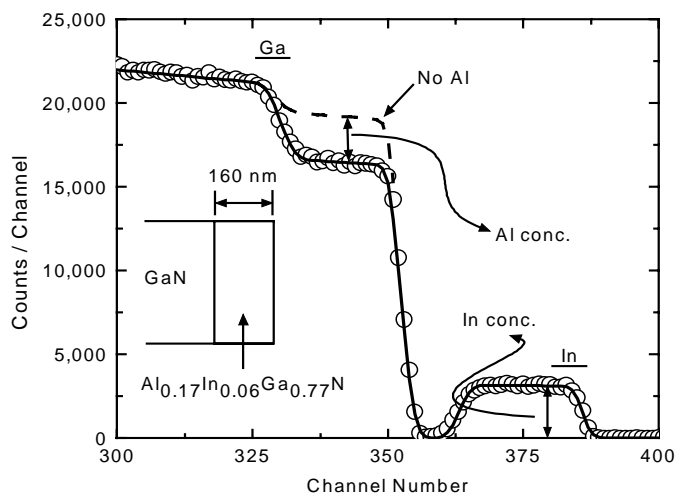

Figure 1. An RBS spectrum from an AlGaInN sample. The solid line is a simulated fit.

A high-resolution triple-axis x-ray diffractometer (Philips X'Pert System) was employed to assess the structural quality and determine both in-plane ( $\boldsymbol{a}$ ) and out-of-plane (c) lattice parameters using symmetric (0002) and asymmetric (202-4) (using grazingincidence) diffractions. Photoluminescence (PL) was measured using a HeCd laser (325 $\mathrm{nm}$ ) as the excitation source in conjunction with a 0.3 meter spectrometer and a UV enhanced CCD detector. Typical excitation level is around $30 \mathrm{~W} / \mathrm{cm}^{2}$. Real time wafer curvature measurements were performed with a multi-beam optical stress sensor (MOSS) ${ }^{7}$ 
modified for use on our reactor. To determine the wafer curvature, the divergence of an array of initially parallel laser beams is measured on a CCD camera after reflection of the array from the film/substrate surface. Changes in wafer curvature induce a proportional change in the beam spacing on the camera. This technique provides a direct measurement of the stress-thickness product during MOVPE of GaN. ${ }^{8}$

In attempting to extract band gap energy from a PL measurement for the AlGaInN quaternary system, one is reminded that the determination of band gap energy for GaInN has been a subject of much debate. ${ }^{9}$ Indium-related compositional fluctuation is expected to contribute to a Stokes-like shift with a magnitude of less than $100 \mathrm{meV} .{ }^{10}$ Fieldinduced separation of electrons and holes (due to piezo- and spontaneous polarization) causes a red shift (up to $300 \mathrm{meV}$ ) of PL emission energy in quantum well structure ${ }^{11}$ but should not be of significance in epilayers thicker than $50 \mathrm{~nm}$. Finally, the existence of a compressive or tensile biaxial strain, due to a combination of lattice mismatch ${ }^{12}$ and thermal mismatch, ${ }^{8}$ introduces a blue or red shift, respectively, to the band gap energy as determined by the deformation potentials. ${ }^{13}$ Given that the In fraction is limited to $10 \%$ and the pseudomorphic strain in the quaternary does not exceed $1 \%$ in compression, we estimate (using published deformation potentials ${ }^{14}$ ) that the difference between PL emission energy and band gap to be less than $100 \mathrm{meV}$ in the epilayers reported here.

\section{RESULTS AND DISCUSSION}

\section{GaN and GaN:In Active region Study}

In our earlier work we have shown an AlGaN/GaN QW LED emitting at a wavelength of $354 \mathrm{~nm}^{2}$ The power output of the prototype UV emitter was around 13 $\mu \mathrm{W}$ at a current level of $20 \mathrm{~mA}$, which is about 2 orders of magnitude lower than the commercial high-brightness blue LEDs. A series of test samples, consisted of $0.5 \mu \mathrm{m}$ of $\mathrm{GaN}$ test layers grown on a standard $\mathrm{GaN}$ epilayer (of $1 \mu \mathrm{m}$ thick), were grown to optimize the optical quality of the active region. Photoluminescence (PL) at room temperature (RT) was employed to measure the optical quality. Among the growth parameters investigated, reactor pressure was found to have a distinct effect on the PL emission intensity. As the growth pressure was increased from 80 Torr (the pressure employed in the previous LEDs and chosen to mitigate the gas-phase reaction during growth of $\mathrm{AlGaN}$ ) to 250 Torr, integrated PL intensity increased by more than 10 times and peaked at around 200 Torr. The mechanism responsible for the observed enhancement of $\mathrm{GaN}$ emission is not known. One might speculate that a reduction of carbon incorporation, due to an increase of the partial pressures of both $\mathrm{NH}_{3}$ and $\mathrm{H}_{2}$, reduces the non-radiative recombination paths. ${ }^{15}$

Recently it has been reported by several groups ${ }^{16,17,18}$ that the addition of a small amount of indium could lead to an enhancement in PL emission efficiency. Mukai et al. ${ }^{16}$ demonstrated an GaN:In UV LED with an indium content of around $2 \%$ and optical power output as high as $5 \mathrm{~mW}$. A series of GaN:In samples $(0.2 \mu \mathrm{m}$ thick on $1 \mu \mathrm{m} \mathrm{GaN}$ epilayers) were grown in which the indium fraction was increased from 0 to approximately $4 \%$ as determined by x-ray and RBS. Figure 1 shows the PL spectrum of the GaN:In layers with the spectrum from an "optimized" $\mathrm{GaN}$ layer as a reference (the bottom trace peaking at $364 \mathrm{~nm})$. At the expense of a shift of emission peak toward longer wavelengths $(\sim 380 \mathrm{~nm})$, we attained an increase of more than one order of magnitude in 
integrated light intensity. Two explanations have been offered to explain the observed enhancement in light emission: carrier localization due to indium incorporation ${ }^{16}$ or the suppression of non-radiative recombination defects in the presence of indium. ${ }^{17}$ Details of the optical investigation will be reported in a separate article in this proceeding. ${ }^{19}$

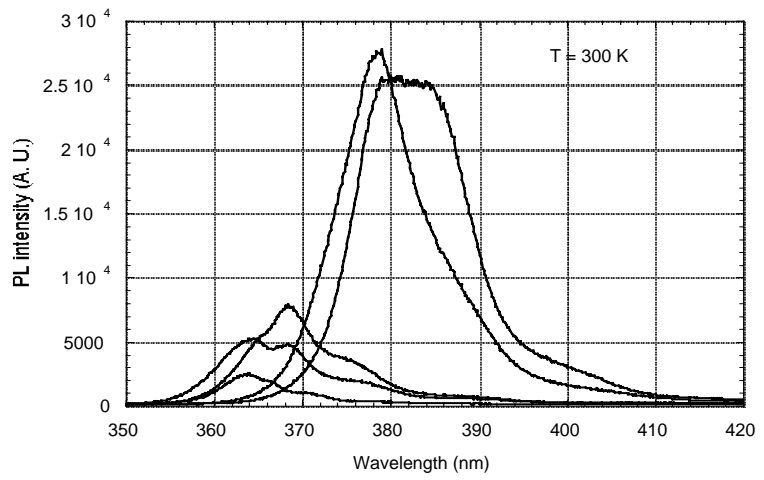

Figure 2. PL of GaInN epilayers with various amount of Indium. The integrated intensity increases by more than 10 times from GaN to $4 \%$ GaInN.

\section{Quaternary AlGaInN}

Only limited information has been published concerning the AlGaInN quaternary system. Matsuoka ${ }^{20}$ predicted the presence of an unstable mixing region (spinodal phase separation) in wurtzite $\mathrm{AlGaInN}$ as the indium content increases. The challenges associated with the growth of AlGaInN, primarily the selection of conditions necessary to enable surface diffusion of $\mathrm{Al}$ and $\mathrm{Ga}$ species while at the same time preventing the surface re-evaporation of In, are partially manifested by the scarcity of experimental data.

McIntosh et al. ${ }^{21}$ and Yamaguchi et al. ${ }^{22}$ reported the physical incorporation of $\mathrm{Al}$ and $\mathrm{In}$ into $\mathrm{GaN}$ by MOVPE. Aiming at proof-of-concept demonstrations of material synthesis, little information was provided in either work concerning the bandgap versus alloy compositions. The functional feasibility of $\mathrm{AlGaInN}$ as a confinement barrier also remained ambiguous in these studies since PL emission (energies) from samples investigated did not exceed the emission (energy) of GaN $(\sim 363 \mathrm{~nm} / 3.42 \mathrm{eV})$ ). The concern was reiterated by Peng et al. ${ }^{23}$ in stating, based on optical absorption measurements of sputtered polycrystalline films, that AlInN and AlGaInN do not seem to provide good confinement (to GaInN) due to a very strong bowing effect. We have shown from in-situ stress measurement that the use of high Al-fraction (or thick) AlGaN barriers on $\mathrm{GaN}$ templates, required for electrical and optical confinement in UV devices, leads to a buildup of tensile stress and subsequently the occurrence of cracking. ${ }^{3}$ As discussed in the above section, introducing indium into GaN greatly enhances the optical efficiency but at the cost of an increase in emission wavelength. Investigation of quaternary $\mathrm{AlGaInN}$ was initiated by the two constraints encountered in the use of 
ternaries $\mathrm{AlGaN}$ and $\mathrm{GaInN}$ as barriers and wells, respectively. It is expected that AlGaInN would render flexibility in controlling the mismatch strain and bandgap profile.

Figure 3 shows (0002) 20- $\omega$ x-ray diffraction (XRD) scans (with an analyzer-crystal detector) for several AlGaInN (a, c-f) and GaInN (b) epilayer samples. Thickness of the samples varies from 0.14 to $0.20 \mu \mathrm{m}$, as indicated by the change of the period of the diffraction fringes. (Thin film thickness derived independently from $\mathrm{x}$-ray fringes and from RBS simulations differed by less than 5\% in most cases.) By adjusting the relative $\mathrm{Al}$ and In compositions, one observes a change of the out-of-plane lattice parameter from being larger (top trace) to smaller (bottom trace) than that of GaN. Pseudomorphic growth is verified by measuring the in-plane lattice parameter $(\boldsymbol{a})$ of the epilayers. Unlike the case in zincblende semiconductor heterostructure, the appearance of an overlap between the (0002) diffraction peak from the quaternary and the peak from GaN (a condition between scans (d) and (e)) does not necessarily imply a lattice-matched strain-free epitaxy as the inplane and out-of-plane lattice parameters of $\mathrm{AlN}, \mathrm{GaN}$, and $\mathrm{InN}$ do not vary in a linear manner. Using the published lattice parameters, ${ }^{12}$ exact match of the $\boldsymbol{a}$ lattice constant of AlInN to GaN should occur at an $\mathrm{Al}$ fraction of $18 \%$ while it takes approximately $28 \% \mathrm{Al}$ in AlInN to match the out-of-plane (c) lattice parameter of GaN. A quaternary compound with a $c$ lattice parameter matched to $\mathrm{GaN}$ is speculated to be under biaxial compression during growth.

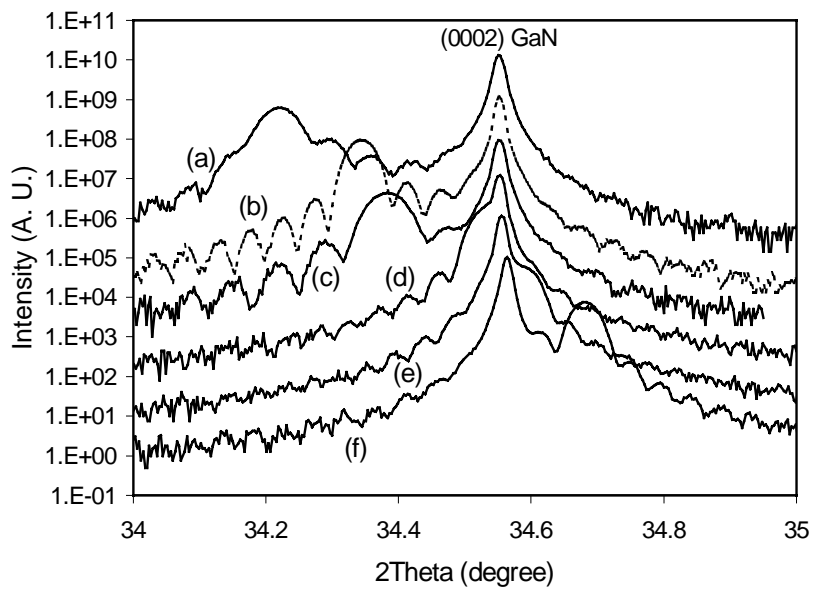

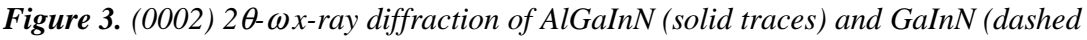
line) epilayers showing a range of lattice parameters bracketing the GaN lattice parameter. The (0002) GaN diffraction peaks move progressively toward higher-angle side as the lattice parameters of the upper alloy layers reduce. 


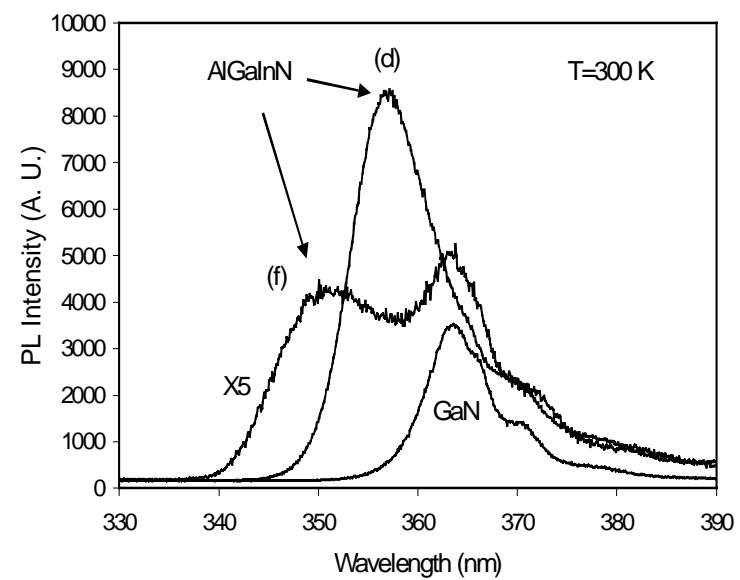

Figure 4. Room-temperature photoluminescence from a GaN (solid line) epilayer and two AlGaInN epilayers (samples $d$ and $f$ ).

Optical properties of the AlGaInN samples (d and f in Figure 3) were investigated with RT PL (Figure 4). The PL from a "standard" GaN epilayer was included for comparison. It is clear from Figure 4 that the $\mathrm{AlGaInN}$ epilayer emits with energy higher than that of $\mathrm{GaN}$. The $\mathrm{Al}_{0.14} \mathrm{Ga}_{0.82} \mathrm{In}_{0.04} \mathrm{~N}$ epilayer (sample (d) in Figures 3 and 4) gives the indication that one can synthesize a wider bandgap (than $\mathrm{GaN}$ ) quaternary AlGaInN compound yet with an in-plane lattice constant larger than that of $\mathrm{GaN}$. It is worth noting that the integrated PL intensity from this quaternary is about three times brighter than that from $\mathrm{GaN}$. There has been much empirical observation and speculation that the presence of indium in GaInN ternary layers seems to preserve excited carriers from recombining at non-radiative centers. ${ }^{24}$ Mukai et al. ${ }^{16}$ reported, in the development of ultra-violet LEDs, a rapid reduction of optical efficiency as the In content in the GaInN active region decreased below a certain value. The implication is that the carrier-localization effect, ${ }^{24}$ possibly due to the presence of a compositional fluctuation of indium, could make $\mathrm{AlGaInN}$ an alternative (to $\mathrm{GaN}$ or $\mathrm{AlGaN}$ ) as a short-wavelength $(\lambda<360 \mathrm{~nm})$ lightemitting medium

For the design and implementation of quaternary heterostructure devices, it is helpful to superimpose contours of constant lattice parameter and "bandgap" (or more precisely, PL peak) energy as functions of the alloy compositions. A series of AlGaInN, GaInN, and $\mathrm{AlGaN}$ epilayers have been grown and the characterizations are summarized in Figure 5. $\mathrm{Al}_{\mathrm{y}} \mathrm{Ga}_{1-\mathrm{x}-\mathrm{y}} \mathrm{In}_{\mathrm{x}} \mathrm{N}$ is described in this work by a right-angle triangle with $\mathrm{AlGaN}$ and GaInN forming the two sides around the right-angle vortex. (The hypotenuse corresponds to the ternary AlInN, not shown in Figure 5.) The location of any $\mathrm{Al}_{\mathrm{y}} \mathrm{Ga}_{1-\mathrm{x}-\mathrm{y}} \mathrm{In}_{\mathrm{x}} \mathrm{N}$ quaternary is uniquely specified by the $\mathrm{In}(\mathrm{x})$ and $\mathrm{Al}(\mathrm{y})$. The triangles, diamonds, and 
circles represent the data points for $\mathrm{AlGaN}, \mathrm{GaInN}$, and $\mathrm{AlGaInN}$, respectively. The compositions of the ternaries were determined primarily by $\mathrm{x}$-ray diffraction and independently confirmed by RBS, the quaternary compositions were determined by RBS. The solid line with a slope of around 4.4 defines the quaternary alloys that are lattice matched to $\mathrm{GaN}$; one can construct an array of parallel lines for lattice-matched growth with different in-plane lattice parameters. (Vegard's law predicts that the in-plane lattice parameter will remain unchanged when the increments of $\mathrm{Al}(\Delta \mathrm{Al})$ and $\mathrm{In}(\Delta \mathrm{In})$ maintain a ratio of 4.44.) Quaternary alloys located to the lower right half of the straight line are expected to be under compression on a GaN template. The distance between a given data point on this plot and the solid line gives a qualitative measure of mismatch-induced strain.

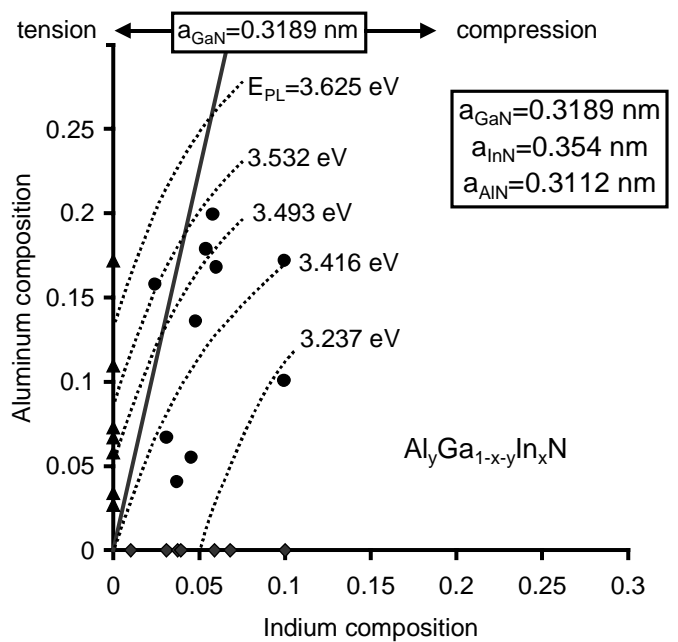

Figure 5. Contour plot of constant (in-plane) lattice parameter and emission energy versus $\mathrm{Al}$ and In compositions for AlGaInN epilayers.

PL investigation of the near band-edge emission is summarized by the dashed curves (denoting contours of constant PL peak energy) in Figure 5. The dashed contours are derived based on two assumptions: i) all the data points should be fitted by contours with nearly identical forms, and ii) the contours should be consistent with the available (theoretical ${ }^{25}$ and experimental ${ }^{26}$ ) bowing information of ternary AlInN. Along each dashed line, the emission wavelength remains constant while the in-plane lattice parameter (and therefore strain) can be adjusted by varying the Al and In fractions. Since the Inrelated Stokes-shift tends to increase with an increasing In composition, the slopes of the contours for the actual bandgap energy might be less steep.

\section{AlGaInN/GaInN Multiple Quantum Wells}

To demonstrate the possibility of heterostructures incorporating quaternary AlGaInN, we have grown multiple quantum well (MQW) structures consisting of 10

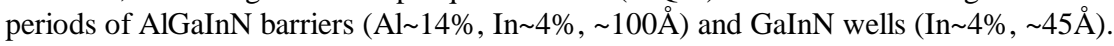


Figure 6 shows the (0002) $2 \theta-\omega$ XRD from the MQW structure. The presence of satellite peaks and other interference fringes is indicative of structural order and coherency (along the growth direction). Cross-sectional TEM images (Figure 7) indicated that the $\mathrm{AlGaInN/GaInN} \mathrm{interfaces} \mathrm{are} \mathrm{smooth} \mathrm{and} \mathrm{coherent} \mathrm{on} \mathrm{the} \mathrm{atomic} \mathrm{scale.} \mathrm{One} \mathrm{also} \mathrm{notices}$ from Figure 6 that the AlGaInN/GaInN MQW has a zero-order peak that corresponds to the lattice constant of a $2.0 \% \mathrm{GaInN}$ alloy. In-situ stress/strain monitoring was conducted during the growth of a similar MQW structure and is shown in Figure 8. While the GaN layer is under tension ${ }^{8}$ during growth $(0.40 \mathrm{GPa})$, the $\mathrm{AlGaInN} / \mathrm{GaInN}$ MQW region is under compression during growth $(\sim 0.47 \pm 0.07 \mathrm{GPa})$. Assuming a compressive thermal mismatch stress of $0.2 \mathrm{GPa}$ from $1050^{\circ} \mathrm{C}$ to $800^{\circ} \mathrm{C}$, one can estimate an average compressive mismatch strain of $0.15 \%$, corresponding to the lattice constant of a $1.4 \%$ GaInN epilayer.

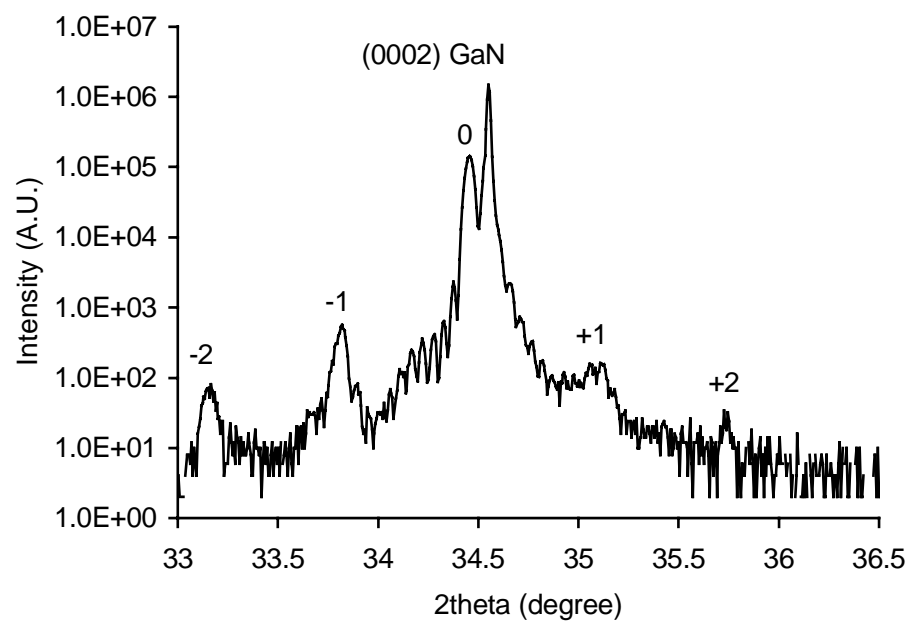

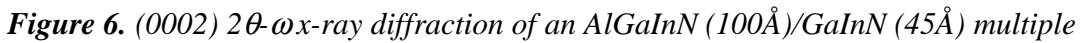
(10) quantum wells.

Optical quality of the AlGaInN/GaN MQWs was investigated using temperaturedependent PL. It is generally assumed that the non-radiative recombination mechanisms are thermally activated and the decay of integrated PL intensity from low temperature to room temperature renders a quantative measurement of the nonradiative processes. ${ }^{27,28}$ Figure 9 shows the temperature-dependent PL with a plot of the integrated intensity in the inset. A reduction of 4.5 times of the integrated PL intensity from $4 \mathrm{~K}$ to $\mathrm{RT}$ is comparable to the best reported for GaInN MQWs emitting at around $450 \mathrm{~nm}{ }^{29}$ This also implies that an upper limit to the internal quantum efficiency of $20 \%$ is obtained at RT. 


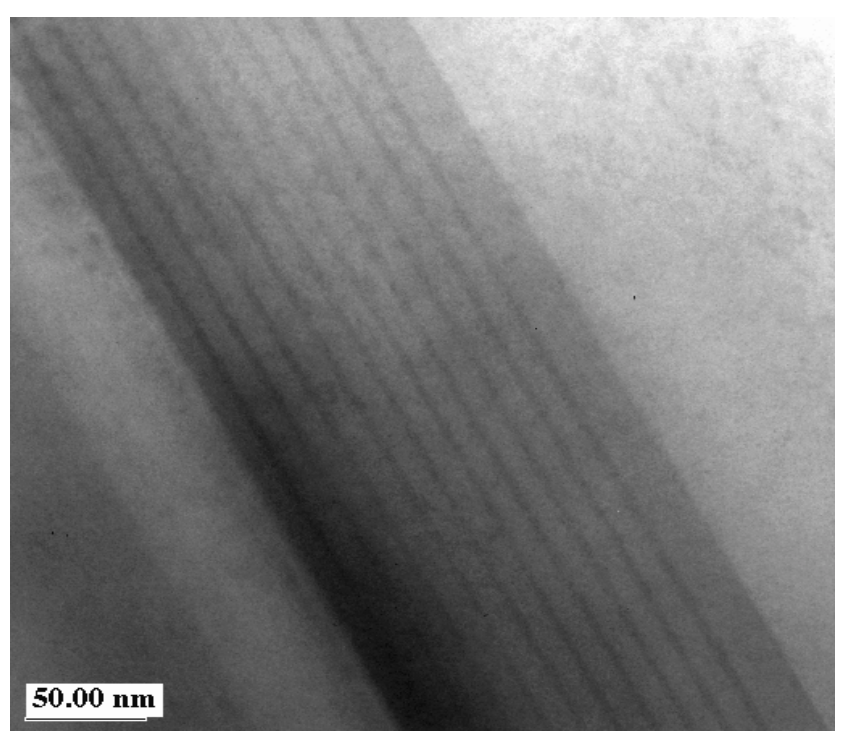

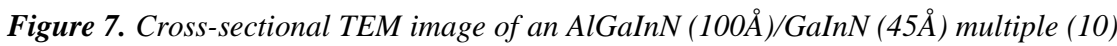
quantum wells.

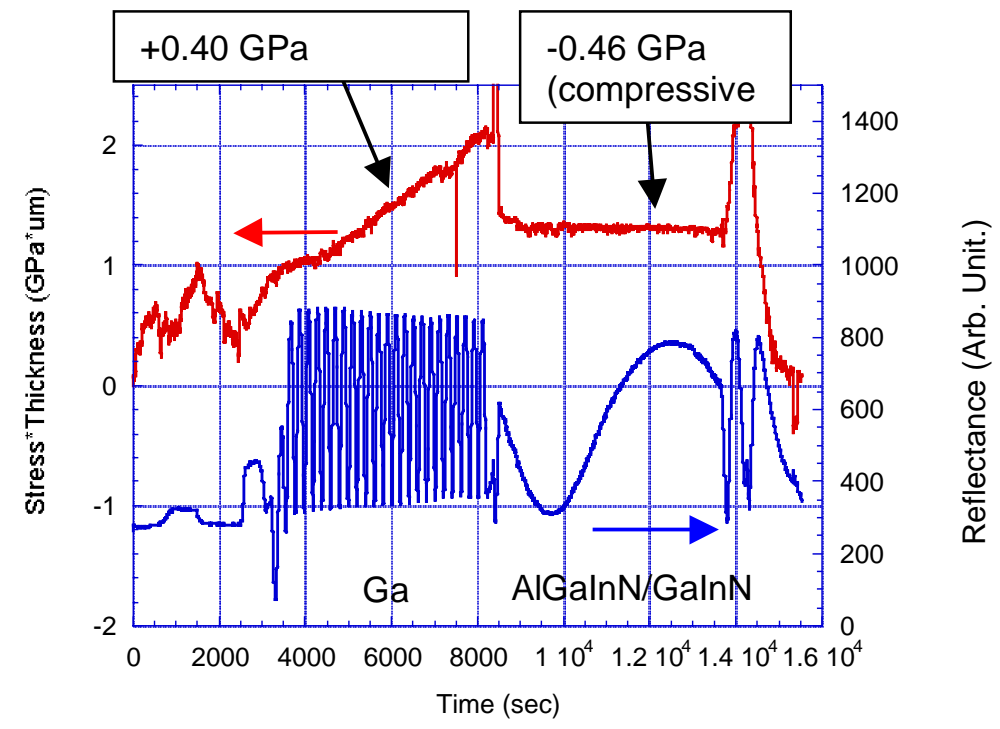

Figure 8. In-situ stress measurement of during growth of an MQW LED. 


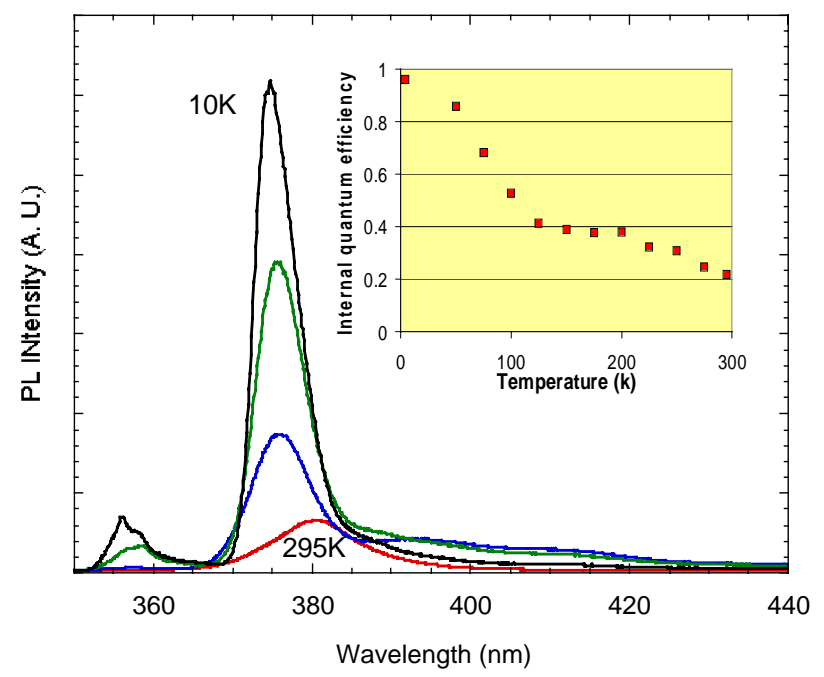

Figure 9. Temperature-dependent PL (at 10, 75, 150, and $295 \mathrm{~K}$ with decreasing intensity) suggesting an internal quantum efficiency of around $20 \%$ from the AlGaInN/GaInN MQWs.

\section{CONCLUSIONS}

In conclusion, we reported the MOVPE growth and characterization of quaternary AlGaInN. Contours of constant PL peak energy and lattice parameter of $\mathrm{AlGaInN}$ were projected onto a two-dimensional plot. We confirmed that the employment of this novel quaternary compound could facilitate the tailoring of energy gap and lattice mismatch for design flexibility. In spite of the previous speculation that strong bowing could hinder the usage as a short-wavelength light emitter, we observed PL emission as short as $351 \mathrm{~nm}$ from a layer with about $20 \% \mathrm{Al}$ and $5 \% \mathrm{In}$. The possibility of replacing $\mathrm{AlGaN}$ as an alternative barrier material was demonstrated through an AlGaInN/GaInN MQW structure.

\section{ACKNOWLEDGMENTS}

The authors acknowledge stimulating interactions with J. Y. Tsao, A. F. Wright, S. R. Lee, and H. Amano (Meijo University). Sandia is a multiprogram laboratory, operated by Sandia Corporation, a Lockheed Martin company, for the United States Department of Energy, under contract DE-AC04-94AL8500. 


\section{REFERENCES}

${ }^{1}$ For a review, see S. Nakamura and G. Fasol, The Blue Laser Diode, Springer-Verlag, Berlin (1997).

${ }^{2}$ J. Han, M. H. Crawford, R. J. Shul, J. J. Figiel, M. Banas, L. Zhang, Y. K. Song, H. Zhou, and A. V. Nurmikko, Appl. Phys. Lett, 73, 1688 (1998)

${ }^{3}$ J. Han, M. H. Crawford, R. J. Shul, S. J. Hearne, E. Chason, J. J. Figiel, and M. Banas, MRS Internet J. Nitride Semicond. Res. 4S1 G7.7 (1999).

${ }^{4}$ J. Han, T. -B. Ng, R. M. Biefeld, M. H. Crawford, and D. M. Follstaedt: Appl. Phys. Lett. 71 (1997) 3114.

${ }^{5}$ W-K. Chu, J. W. Mayer, and M.-A. Nicolet: Backscattering Spectrometry (Academic, New York, 1978).

${ }^{6}$ M. Mayer: SIMNRA User's Guide, Technical Report IPP 9/113 (Max Planck-Institut fur Plasmaphysik, Garching, Germany, 1997).

${ }^{7}$ C. Taylor, D. Barlett, E. Chason, J. A. Floro, Ind. Physicist 4, 25 (1998)

${ }^{8}$ S. Hearne, E. Chason, J. Han, J. A. Floro, J. Hunter, J. J. Figiel: Appl. Phys. Lett. 74 (1999) 356.

9 T. Takeuchi, H. Takeuchi, S. Sota, H. Sakai, H. Amano, and I. Akasaki: Jpn. J. Appl. Phys. 36 (1997) L177; S. Nakamura and T. Mukai: J. Vac. Sci. Tech. A 13 (1995) 705.

${ }^{10}$ S. Chichibu, T. Azuhata, T. Sota, and S. Nakamura: Appl. Phys. Lett. 70 (1997) 2822; S. F. Chichibu, A. C. Abare, M. P. Mack, M. S. Minsky, T. Deguchi, D. Cohen, P. Kozodoy, S. B. Fleischer, S. Keller, J. S. Speck, J. E. Bowers, E. Hu, U. K. Mishra, L. A. Coldren, S. P. DenBaars, K. Wada, T. Sota, and S. Nakamura: Mat. Sci. Eng. B59 (1999) 298.

${ }^{11}$ S. Chichibu, T. Deguchi, T. Sota, K. Wada, and S. Nakamura: Mat. Res. Soc. Symp. Proc. 482 (1998) 613.

${ }^{12}$ O. Ambacher, J. Phys. D: Appl. Phys. 31, 2653 (1998).

${ }^{13}$ C. Kisielowski, J. Kruger, S. Ruvimov, T. Suski, J. W. Ager III, E. Jones, Z. LilientalWeber, M. Rubin, E. R. Weber, M. D. Bremser, and R. F. Davis: Phys. Rev. B 54 (1996) 17745.

${ }^{14}$ S. Chichibu, A. Shikanai, T. Azuhata, T. Sota, A. Kuramata, K. Horino, and S. Nakamura, Appl. Phys. Lett. 68, 3766 (1996)

${ }^{15}$ S. M. Bedair, Gallium Nitride (GaN) I, Semiconductors and Semimetals, v50, p127 (1998), Academic Press, San Diego

${ }^{16}$ T. Mukai, D. Morita, and S. Nakamura, J. Cryst. Growth 189/190, 778 (1998)

${ }^{17}$ Y. Narukawa, S. Saijou, Y. Kawakami, S. Fujita, T. Mukai, and S. Nakamura, Appl. Phys. Lett. 74, 558 (1999)

${ }^{18}$ X. Shen and Y. Aoyagi, Jpn. J. Appl. Phys. 38, L14 (1999).

${ }^{19}$ M. H. Crawford et al., Mat. Res. Soc. Symp.Proc. for Fall MRS Meetings, 1999.

${ }^{20}$ T. Matsuoka: Appl. Phys. Lett. 71 (1997) 105.

${ }^{21}$ F. G. McIntosh, K. S. Boutros, J. C. Roberts, S. M. Bedair, E. L. Piner, and N. A. ElMasry: Appl. Phys. Lett. 68 (1996) 40; S. M. Bedair, F. G. McIntosh, J. C. Roberts, E. L. Piner, K. S. boutros, N. A. El-Masry: J. Cryst. Growth 178 (1997) 32.

${ }^{22}$ S. Yamaguchi, M. Kariya, S. Nitta, H. Kato, T. Takeuchi, C. Wetzel, H. Amano, and I. Akasaki: J. Cryst. Growth 195 (1998) 309.

${ }^{23}$ T. Peng, J. Piprek, G. Qiu, J. O. Olowolafe, K. M. Unruh, C. P. Swann, and E. F. Schubert: Appl. Phys. Lett. 71 (1997) 2439. 
${ }^{24}$ S. F. Chichibu, H. Marchand, M. S. Minsky, S. Keller, P. T. Fini, J. P. Ibbetson, S. B. Fleischer, J. S. Speck, J. E. Bowers, E. Hu, U. K. Mishra, S. P. DenBaars, T. Deguchi, T. Sota, and S. Nakamura: Appl. Phys. Lett. 74 (1999) 1460.

${ }^{25}$ A. F. Wright and J. S. Nelson: Appl. Phys. Lett. 66 (1995) 3051; A. F. Wright and J. S. Nelson: Appl. Phys. Lett. 66 (1995) 3465.

${ }^{26}$ K. S. Kim, A. Saxler, P. Kung, M. Razeghi, and K. Y. Lim: Appl. Phys. Lett. 71 (1997) 800.

${ }^{27}$ M. Leroux, N. Grandjean, B. Beaumont, G. Nataf, F. Semon, J. Massies, and P. Gibart, J. Appl. Phys. 86, 3721 (1999).

${ }^{28}$ Y. Narukawa, Y. Kawakami, S. Fujita, and S. Fujita, Phys. Rev. B 55, R1938 (1997).

${ }^{29}$ S. F. Chichibu, private communication (1999). 